\title{
Changing to Minimal Reliance on Pesticides
}

\author{
Paul A. Horne and Jessica Page \\ IPM Technologies Pty Ltd \\ Australia
}

\section{Introduction}

The most commonly accepted method of controlling pests in Australian crops and throughout the world is the use of pesticides (eg.Pimental 1997, Pimental et al. 1997, Page and Horne 2007). There is a reliance on pesticides and the majority of farmers look to chemical companies to continue to provide the familiar means with which they can deal with the complete range of pests that are of concern. In 1997 Pimental et al estimated that US farmers used 400 million $\mathrm{kg}$ of pesticides annually and worldwide 25 million tonnes of pesticides were applied. An example of the dependence on pesticides can be seen by the close association between the primary producer organizations and pesticide companies and resellers. For example, in Australia, there is an acknowledged strong association between the vegetable industry, as represented by AusVeg (see http://ausveg.com.au) where chemical industry sponsorship of the organization is seen as desirable by both groups. This is alongside an acknowledged effort to implement IPM in vegetables crops in Australia by both AusVeg and several chemical companies. Similarly the Grains Research and Development Corporation (GRDC) in Australia would like to be seen as promoting IPM but the reality is that pesticide applications are the main controls used.

However, there are many examples worldwide of a desire to reduce reliance on pesticides and one particular example of this is by the adoption of integrated pest management (IPM) strategies. It is an approach that is widely seen as desirable and is promoted by many agencies worldwide, including the United Nations, the World Bank and the Food and Agriculture Organisation (FAO) (Maredia 2003, Olsen et al. 2003) and also government agencies in Australia (Williams and Il'ichev 2003). Despite this support the change to using this approach is often slow, even though there are examples of success and proven methods of implementing IPM strategies. So, can we successfully reduce our reliance on pesticides if farmers and their advisors do not adopt the strategies that scientists have developed? Also, have scientists developed strategies that are too narrow in design, by dealing with only a narrow pest spectrum?

In this paper we look at what is required to implement change, specifically regarding pest management practices so that there is less reliance on applications of pesticides. The reasons for wanting to reduce reliance on pesticides include insecticide resistance, destruction of natural enemies and other non-target species, residues in produce, environmental concerns and effects on human health (Perkins and Patterson 1997).

\subsection{IPM}

Integrated Pest Management (IPM) is the use of all available control measures used in a compatible way, but in our opinion should be based on biological and cultural controls with 
pesticides used only as support tools. The use of these support tools is decided on the results of monitoring of both pest and beneficial species. The basis of this paper is that adoption of IPM is the best method to reduce reliance on pesticides (Perkins and Patterson 1997). This is supported by many publications over many years, (see Table 1 and Horne et al. 2008). So the change to minimal reliance on pesticides depends largely on the adoption of IPM strategies which are based on biological and cultural controls.

\section{Advantages of IPM}

Reduced dependence on pesticides

Increased safety to farm workers, spray operators and the community

A slower development of resistance to pesticides

Reduced contamination of food and the environment

Improved crop biodiversity

\section{Disadvantages of IPM}

More complex than control by pesticide alone and requires a shift in understanding

Requires a greater understanding of the interactions between pests and beneficials

Requires a greater understanding of the effects of chemicals

Increased time and resources

Level of damage to the crop may initially increase during transition to an IPM programme, in some horticultural crops

Table 1. Advantages and disadvantages of adopting IPM

There are also very many publications that report the fact that levels of adoption of IPM are very often low and rates of adoption are slow (Bajwa and Kogan 2003, Herbert 1995, McNamara et al. 1991, Olsen et al. 2003, Sivapragasam 2001, Wearing 1988). Even in horticultural crops where the theory of IPM is well developed, achieving widespread adoption on farms remains a challenge (Page and Horne 2007; Boucher and Durgy 2004). ). There is a very simple reason for the low rates of adoption of IPM - and it is that the current methods (pesticide applications) are still effective, are legal, and are familiar. There is only a general desire to do something different when this set of reasons is not true. That is, there is a desire to find a new method of pest control when either the pesticides fail (insecticide resistance), or the pesticides are no longer available (withdrawn or banned). Then the pressure to try something unfamiliar becomes more compelling.

The way in which information about IPM is presented, and indeed what is presented, is something that is contentious amongst IPM workers around the world, and we of course have our own opinion. There is a large amount of information available, including websites, CD-ROMs, videos, posters and information sheets that are used to provide farmers with the necessary information. Direct contact with farmers is also an option but even this is not an assured method of adoption.

We have a different view on the presentation of IPM information to most (but certainly not all). We believe that there is a scientific basis to the method of presenting IPM that we use, and also that there is a great distinction between information that increases awareness of IPM and that which increases adoption of IPM. 


\subsection{What information is presented? Entomologists presenting advice on individual species, farmers dealing with whole crop}

An extremely important aspect of advice given about pest management, and in particular pesticide applications, is how wide the consideration is given to the impact of any application. That is, if any action, including pesticide application, was made with the aim of controlling any particular pest, then what consideration is made as to the impact on the control of other pest species? It is not only the degree of control of the target pest achieved by a pesticide application that may have been applied, but also the effect of that pesticide on the biological control agents of other pests.

For example, a key target pest in brassica crops is Plutella xylostella (diamondback moth). It is certainly not the only pest in brassica crops but this has been sometimes forgotten by entomologists focusing on this pest. (Given the importance of this species of pest it is understandable that there would be an over-emphasis on this pest alone). The focus was created because of the insecticide resistance that developed in P. xylostella in strategies of pest control that were based on insecticide applications alone. An outcome of the singular focus on diamondback moth has been the presentation to brassica growers of strategies labelled in terms such as an: "IPM Strategy for Diamondback Moth". This obviously does not consider the full range of pests, or actions that brassica growers may need to make to deal with a range of pests including other caterpillars and aphids, or the beneficial species that contribute to the control of all of these pests. What is required is an IPM Strategy for Brassica Crops.

The development of strategies based on pesticides to control P. xylostella include insecticide resistant management strategies (IRM) and this has been the focus of some researchers in Australia(eg:[http://www.sardi.sa.gov.au/pestsdiseases/horticulture/horticultural_pests/ diamondback_moth/insecticide_resistance_management]. Whether or not these strategies work on control of P. xylostella is not the only consideration for a brassica grower. To have a brassica such as broccoli or cauliflower accepted by the market there must be adequate control of a range of pests, not just $P$. xylostella. A broccoli or Brussels sprouts crop free of $P$. xylostella but infested with aphids is still not acceptable in the market. What this means of course is that a brassica grower needs to have a strategy to control all pests, not just some. Research entomologists can mistake the target pest on which they are working as the only pest to be considered.

\subsection{Disruption of biological control}

The IRM strategies that have been developed in various places are examples of how advice on how to control one pest (for example the major pest) can disrupt control of other pests. This is because pesticides that may kill the major pest will also kill the beneficial species that control other pests. This is the most serious problem with pesticide applications in most cases. However, there are other effects that can and do influence the control of pests other than the major pest.

One example is when some of the newer pesticides such as emmamectin ("Proclaim") or indoxacarb ("Avatar") are sprayed for the control of caterpillar pests. These are much more selective than organophosphate and synthetic pyrethroid insecticides and can be used within IPM strategies but their impact on the beneficial species that control other pests can still be significant. For example, emmamectin will kill wasp parasitoids and also predatory bugs such as Nabis conformis and indoxacarb will kill a range of beneficial species but is not particularly residual (www.ipmtechnologies.com.au). So the application of these pesticides 
may achieve the immediate aim of killing target caterpillar pests, but in the process there will be a loss of the biological control agents that are required for on-going and sustainable control. In addition, the control of other pests such as aphids or mites could easily be disrupted because of the loss of a different set of beneficial species. This does not mean these products must never be used but the impact of using them needs to be understood before they are applied. In particular, what species of beneficials are present and is there the possibility of re-invasion of these species?

A common desire amongst many farmers and agronomists, and even some entomologists, is to produce a list rating pesticides as "safe" or "not safe" in absolute terms, not taking into consideration the effect on different species of beneficials. This simplistic approach can be a major setback for IPM adoption as growers tend to simply shift to using less-broadspectrum insecticides and think they are using IPM. What is required is detailed information on the effects (acute and sub-lethal) of each pesticide on each particular species.

\subsection{Awareness versus adoption}

There is a tendency amongst some entomologists to concentrate more on awareness of IPM than adoption of IPM. While there needs to be awareness before there can be adoption, the adoption step requires a different set of skills and is something that some organizations promoting IPM would rather avoid. Awareness of IPM may involve talks, workshops, videos, leaflets, manuals, DVD's etc and the production of these tools is a more attractive option to many public organizations as they would seem to be able to reach a large number of people and involve little risk. However, adoption, or implementation, of those practices requires a further step to be taken by the farmer even when there may be awareness of what is possible with IPM. There are different steps needed to implement the change to a totally different method of pest management to that which has been used by the farmer and is familiar.

\subsection{What is required to implement change?}

In many cases the catalyst for making the change to something unknown (ie IPM) occurs when there is a crisis in pest control, because either the pesticides that have been relied on stop working (insecticide resistance) or the pesticide is no longer available (eg registration withdrawn or the product is withdrawn from sale). While there are other factors that influence the decisions on whether or not to use a pesticide-based strategy (referred to in chapter 2) these two are the most common reasons for a sudden increase in adoption of IPM. Obviously if the methods that are being used no longer work then something different must be done to control pests. In such circumstances farmers are more naturally responsive to embrace a different approach, and examples of different reasons for making changes are given later in this chapter.

It is entirely possible to have farmers understand and implement IPM without any particular crisis. The key factors to success are well documented (eg Herbert 1995) and involves the collaborative and participatory approach to working with individual or small groups of farmers and providing expert, site-specific advice when required.

\subsection{Familiar versus different}

There is a common experience from a farmer's (or advisor's) point of view when deciding between whether to use a pesticide-based strategy or an IPM strategy. When the starting 
point for any individual farmer or farm is that a pesticide-based strategy is known, legal and it works then the decision to adopt something unfamiliar and unproven (on the farmer's own crop) is extremely difficult and is seen as unnecessary and risky. One way to reduce the perceived risk is to have regular monitoring of both pests and beneficial species conducted, in order to check that the desired biological control component of IPM is working as expected.

\subsection{The role of monitoring}

Monitoring does not control any pests! The reason for saying this is that very often, in our experience, farmers expect that because their crop is being monitored by professional crop monitors then there will automatically be a decrease in pest problems. The only reason for conducting monitoring is to allow timely and informed decisions to be made. Monitoring will allow an assessment to be made about the risk of economic damage by any particular pest. This will include an assessment as to the degree of likely biological control.

\subsection{Information on pesticides}

It may seem strange at first, but the most important information required to help implement IPM and especially the biological control component, is knowledge about pesticides. This includes information about the impact of pesticides on beneficial species but also involves information about the correct selection of pesticides (including fungicides) for any given problem and in particular to ensure that the pesticide application achieves the result that is desired. Again, it may seem surprising but the practical limitations such as weather and temperature, water volume, adjuvants that should be used with different products are not always (or often) known by farmer or their advisors (including chemical re-sellers).

In an IPM strategy insecticides are used as a support tool when biological and cultural controls are assessed by monitoring as not being sufficient to give adequate levels of control. It is therefore absolutely essential that any application of pesticide is well-timed and correctly applied or else it will not achieve the intended aim of supporting the other control elements. Too often this aspect of IPM is not implemented well. Although research may be done by entomologists (including us) to evaluate the impact of pesticides on beneficial species, it needs to be applied. That is, farmers need to be able to use that information, not just hear about it.

This brings into question the role of entomologists as researchers as opposed to advisors. Worldwide there has been a huge investment in IPM research, and it is the same in Australia. The problem for investors in this research is that there has been a poor level of adoption of IPM as a result of research and the question is why? The answer, we believe, is that researchers do not usually sell or market IPM the way a chemical company or reseller can sell a chemical. What is required is for IPM (and the research that has developed IPM strategies) to be brought into the commercial world rather than stay in the (usually) public funded research environment.

Given that there are only three control options for pest management (biological, cultural or chemical) then it is essential that all three methods work in collaboration, not in opposition. The biological controls in most cases are naturally occurring and cannot be manipulated (apart from not being killed) and cultural controls are usually underestimated. This means that for the farmer, the association between pesticide application and pest control is still paramount. The advisor or crop monitor may know more, but the farmer will be tempted to measure pest control with sprays applied. This means that the decision-making that leads 
to a pesticide application needs to be absolutely site-specific and take into account the many factors that may be influencing any decision (eg. pest pressure, levels of beneficials, types of beneficials, the observed trend in success of biocontrol, time until harvest, age of crop, time of year, stages of pests, stages of beneficials, intended market etc). These many factors are too many for a general advisory note to include and so site-specific advice is what is needed.

\subsection{Collaboration (participatory trials)}

We believe that the best way to implement a change to the adoption of IPM is by farmers and advisors working together to obtain site-specific solutions. However, if this is not possible because a lack of such advisors then there are still great changes and advances that farmers can make. With the current technology of the internet, e-mail and digital photos available (and it is certain to improve still more) it is possible to find information and advice relating to the above points. There may not be absolute information regarding particular pest/crop/pesticide/location, but there is usually some information regarding the relative toxicity of pesticides to a range of species (eg. side-effects guides on web-sites such as www.koppert.com). Using the available information a farmer can begin to make changes to what has been the major decision involved in pest management - namely, "what should be sprayed". An option in this decision that involves relying on biological and cultural controls is the option to spray nothing. Information on what pesticides do to a range of beneficial species and not just the pests is the most important tool that most will need to begin to make changes to pest management.

Once the change in pesticide application has been trialled then the farmer may also be more interested in looking at what cultural controls can be utilized along with the different spray regime. Again, information relating to cultural controls can be found or potential (historical/ colloquial) methods trialled on-farm without risking the entire crop.

\section{Examples of implementing change: Case studies}

\subsection{Colin Hurst, Arable cropping farmer, Canterbury, NZ}

Colin Hurst runs a 700 ha family farm near Waimate in the southern Canterbury region of New Zealand. The main crops grown are wheat, grass seed, brassica seed and he also grazes sheep. Cropping accounts for $60 \%$ of the farm area each year.

Prior to 2006 Colin was operating a conventional system using synthetic pyrethroid sprays ("Karate") as the main defence against aphids and the barley yellow dwarf virus that they can vector. However, in 2006 Colin had an introduction to the concept of IPM via a project initiated by the Foundation for Arable Research (FAR). The initial discussion that aroused Colin's interest was that the sprays applied for aphid control could be causing disruption of the control of other pests, and in particular slugs. In wet years slugs were a significant problem and were expensive to deal with (using baits).

The idea of an IPM approach sounded interesting, especially as it offered an alternative to over-reliance on a single insecticide and the development of resistance, but it was also very different to the mainstream approach being used at the time in New Zealand. The idea of seeing pests increase in number but not applying an insecticide spray was one of the biggest changes to be made and one of the biggest concerns in the early stages. So Colin trialled the approach on half a paddock. This allowed him to see the results of each method and compare the results not only in terms of cost of pesticides (including baits) but also in terms of yield. 
The first year's trial was very encouraging, with no pest issues, reduced pesticide use and an increased awareness of beneficial species. Colin had back-up with insect monitoring and decision-making during this time from Plant and Food Research (a government agency in New Zealand) and IPM Technologies P/L visiting from Australia as a part of the project. The realisation that there were many beneficial species present in his crops was something that Colin had not utilised before and he decided that he should investigate further.

Therefore, in the next 2 years of the 3 year project, Colin progressively adopted an IPM approach as he felt more comfortable with the new IPM strategy and decision-making based on monitoring. The monitoring that he uses consists of direct searching for a range of predators and parasitoids, sticky traps to assess what is flying at any time, aphid flight information provided by the Foundation for Arable Research (with Plant and Food Research). Using IPM has meant a much greater use of monitoring than in the past and so any action is based largely on observations on the farm rather than pre- determined sprays or district - wide information. Colin now uses seed dressings of synthetic insecticides rather than sprays as a part of the strategy to use minimal insecticides and instead relies on cultural and biological controls.

The change has been dramatic and in 2010 (4 years after implementing change) the only slug problems requiring treatment was on a border with a neighbours field where there was invasion from outside the farm. The only control measure required in this case was a border application of slug bait. Colin now believes that carabid beetles provide a significant level of control of slugs and is keen not to disrupt this control with sprays targeting aphids.

After 3 years of trials Colin now implements an IPM strategy over the entire farm, and only uses selective insecticides to support the biological and cultural controls as necessary. Although initially daunting, the change in practice has proved worthwhile.

\subsection{IPM at Henderson hydroponics, Tasmania}

(This is the basis of an article published by Good Fruit and Vegetables magazine in 2009 that describes the change to using IPM with the assistance of the authors of this chapter).

Rob Henderson (and his family) grow hydroponic capsicums near Devonport in Tasmania and experienced major problems during the 2007 - 8 season with tomato spotted wilt virus (TSWV). This virus affects the plant and the fruit, causing affected fruit to be unsalable. The only treatment of infected plants is their removal and disposal which resulted in approximately $75 \%$ of TSWV susceptible cultivars being removed prior to the end of the season, which resulted in considerable financial pain. The problem virus is spread by several species of thrips, including western flower thrips (WFT) which had not previous been present at Henderson Hydroponics. WFT are resistant to many insecticides and that was the problem in this case. The thrips were surviving the insecticides that were used and so were literally out of control. Rob needed to do something different to manage these pests and insecticides did not look like the answer.

In 2008 before his latest crop was planted he met with Dr Paul Horne and Jessica Page of IPM Technologies to discuss implementing an IPM approach. Paul and Jessica were in Tasmania to help develop IPM in a range of vegetable crops and were introduced to Rob by an agronomist (Peta Davies from Roberts Ltd) who saw that this may be the answer to their problem.

A range of predators were introduced throughout the season to control fungus gnats, WFT, aphids and two-spotted mite. It also meant that the broad-spectrum insecticides that he 
had used in the past could no longer be used, and extreme care had to be taken to ensure that these beneficial species were not disrupted by attempts to control other pests .

Rob admits "We were sceptical at first about IPM, but now we are converts". He said that "The western flower thrips were present in the latest crop but the predators, in time, controlled them and total damage was reduced to below $2 \%$ infection, down from $75 \%$ the previous year". Two spotted mite were becoming an increasing problem in previous seasons. However excellent control was achieved with the release of Persimilis, which displayed a ravenous appetite for two spotted mite.

There were some very nervous moments early on in the season when WFT were obviously present and before the predatory mites (known as cucumeris) had taken control of the pests. However, the results later in the season speak for themselves and the next seasons expanded crop will again be grown using IPM, but with less nervousness now that Rob knows what to expect.

Rob will be trialling a new thrips predator called Orius that is a new possibility for WFT control. It is being produced in WA.

The project that allowed this to happen is funded by Horticulture Australia and the AusVeg levy.

Rob estimates in his first year of IPM he would have spent approximately treble that which he would have normally spent on insecticide. However he is hopeful that next season, having had a season of IPM experience behind him, this cost may reduce. However as a qualified agricultural economist Rob considers the expenditure on IPM in his greenhouses to be an extremely sound and profitable investment both financially and environmentally.

Henderson Hydroponics staff enjoy working in an environment free of insecticides and have noted the dramatic increase in natural predators, particularly frogs and lady birds seen this season in the greenhouses.

Henderson Hydroponics customers have also been pleased to purchase quality fruit grown without the use of insecticides.

\subsection{What has Henderson hydroponics learnt from one season of IPM?}

- IPM does work.

- Constant crop monitoring is very important.

- Don't be afraid of seeing small numbers of pests, leave the insecticide locked in the chemical store and only think about using it as a last resort.

- Predators take time to multiply. If pest numbers are increasing, purchase and release more predators rather than waiting for predators to breed up.

- Good advice is readily available. Make use of it. Henderson Hydroponics are extremely grateful for the advice provided by Paul and Jessica during their visits and by them being available to answer questions on the telephone and email at short notice.

\section{Conclusion}

Reduction of the current reliance on pesticides for the control of pests in agriculture will be best achieved by the adoption of IPM strategies. The poor results (overall) with regard to adoption of IPM is explained in large part by the poor use of known strategies (participatory research) and the fact that IPM is still largely associated with the publicly funded (Government) organisations rather than with commercial aims. It is essential that IPM adoption shifts to the commercial sector to compete with pesticide focussed strategies. 


\section{Acknowledgements}

We thank the many farmers that we have worked with over the last two decades who have allowed us to suggest changes to their pest management practices. We also thank Peter Cole and Neil Hives for discussions on the best methods to implement IPM in a range of crops.

\section{References}

Bajwa, W.I. and Kogan, M. (2003). IPM adoption by the global community. pp 97 - 107. in Integrated Pest Management in the Global Arena. 512pp. Maredia, K.M., Dakouo, D. and Mota-Sanchez, D. (eds). (CABI Publishing, UK.)

Boucher, T.J. and Durgy, R. (2004). Moving towards ecologically based pest management: A case study using perimeter trap cropping. Journal of Extension 42, (6) Available online at http://www.joe.org/joe/2004december/a2.shtml

Herbert, D. A. Jr. (1995). Integrated Pest Management Systems: Back to Basics to overcome Adoption Obstacles. Journal of Agricultural Entomology. 12, 203 - 210.

Horne, P.A. and Page, J. (2008). Integrated Pest Management for Crops and Pastures. 119pp. Landlinks Press, Australia.

Horne, P.A., Page, J. and Nicholson, C. (2008). When will IPM strategies be adopted? An example of development and implementation of IPM strategies in cropping systems. Australian Journal of Experimental Agriculture. 48: 1601 - 1607.

Maredia, K. M. (2003). Introduction and overview. pp1-8 in Integrated Pest Management in the Global Arena. 512pp. Maredia, K.M., Dakouo, D. and Mota-Sanchez, D. (eds). (CABI Publishing, UK.)

McNamara, K.T., Wetzstein, M.E. and Douse, G.K. (1991). Factors affecting peanut producer adoption of integrated pest management. Review of Agricultural Economics 13, 129 139.

Olsen, L., Zalom, F. and Adkisson, P. (2003). Integrated Pest Management in the USA. pp249 - 271 in Integrated Pest Management in the Global Arena. 512pp. Maredia, K.M., Dakouo, D. and Mota-Sanchez, D. (eds). (CABI Publishing, UK.)

Page, J. and Horne, P.A. (2007). Final Report to Horticulture Australia Limited. Project VG06086: Scoping Study on IPM Potential and Requirements. Available online at http:/ / www.horticulture.com.au

Perkins, J.H. and Patterson, B.R. (1997). Pests, Pesticides and the Environment: A historical perspective on the prospects for pesticide reduction. pp 13 - 33 in Techniques for Reducing Pesticide Use 444pp. Pimental, D (ed). (Wiley, UK).

Pimental, D. (1997). Pest Management in Agriculture. pp1 - 11 in Techniques for Reducing Pesticide Use 444pp. Pimental, D (ed). (Wiley, UK).

Pimental, D.,Friedman, J. and Kahn, D. (1997). Reducing insecticide, fungicide and herbicide use on vegetables and reducing herbicide use on fruit crops. pp379 - 397 in Techniques for Reducing Pesticide Use 444pp. Pimental, D (ed). (Wiley, UK).

Sivapragasam (2001). Brassica IPM adoption: progress and constraints in south-east Asia. Available online at http:/ / www.regional.org.au/au/esa/2001/03/0301siva.htm 
Wearing, C.H. (1988). Evaluating the IPM Process. Annual Review of Entomology 33, 17 38.

Williams, D.G. and Il'ichev, A.L. (2003). Integrated Pest Management in Australia. p371 384 in Integrated Pest Management in the Global Arena. 512pp. Maredia, K.M., Dakouo, D. and Mota-Sanchez, D. (eds). (CABI Publishing, UK.) 


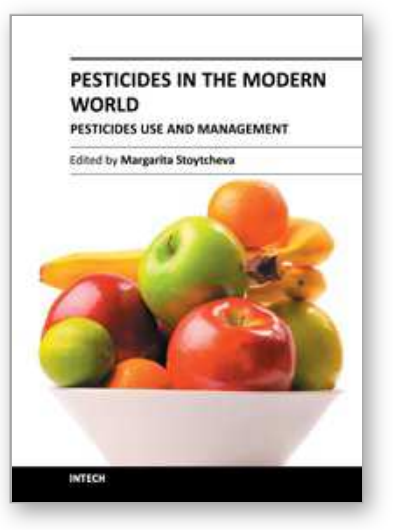

\author{
Pesticides in the Modern World - Pesticides Use and Management \\ Edited by Dr. Margarita Stoytcheva
}

ISBN 978-953-307-459-7

Hard cover, 520 pages

Publisher InTech

Published online 19, October, 2011

Published in print edition October, 2011

This book brings together issues on pesticides and biopesticides use with the related subjects of pesticides management and sustainable development. It contains 24 chapters organized in three sections. The first book section supplies an overview on the current use of pesticides, on the regulatory status, on the levels of contamination, on the pesticides management options, and on some techniques of pesticides application, reporting data collected from all over the world. Second section is devoted to the advances in the evolving field of biopesticides, providing actual information on the regulation of the plant protection products from natural origin in the European Union. It reports data associated with the application of neem pesticides, wood pyrolysis liquids and bacillus-based products. The third book section covers various aspects of pesticides management practices in concert with pesticides degradation and contaminated sites remediation technologies, supporting the environmental sustainability.

\title{
How to reference
}

In order to correctly reference this scholarly work, feel free to copy and paste the following:

Paul A. Horne and Jessica Page (2011). Changing to Minimal Reliance on Pesticides, Pesticides in the Modern World - Pesticides Use and Management, Dr. Margarita Stoytcheva (Ed.), ISBN: 978-953-307-459-7, InTech, Available from: http://www.intechopen.com/books/pesticides-in-the-modern-world-pesticides-use-andmanagement/changing-to-minimal-reliance-on-pesticides

\section{INTECH}

open science | open minds

\author{
InTech Europe \\ University Campus STeP Ri \\ Slavka Krautzeka 83/A \\ 51000 Rijeka, Croatia \\ Phone: +385 (51) 770447 \\ Fax: +385 (51) 686166 \\ www.intechopen.com
}

\author{
InTech China \\ Unit 405, Office Block, Hotel Equatorial Shanghai \\ No.65, Yan An Road (West), Shanghai, 200040, China \\ 中国上海市延安西路65号上海国际贵都大饭店办公楼 405 单元 \\ Phone: +86-21-62489820 \\ Fax: $+86-21-62489821$
}


(C) 2011 The Author(s). Licensee IntechOpen. This is an open access article distributed under the terms of the Creative Commons Attribution 3.0 License, which permits unrestricted use, distribution, and reproduction in any medium, provided the original work is properly cited. 